\title{
Ectopic varices in a pancreatojejunal anastomosis: a rare cause of hemorrhage
}
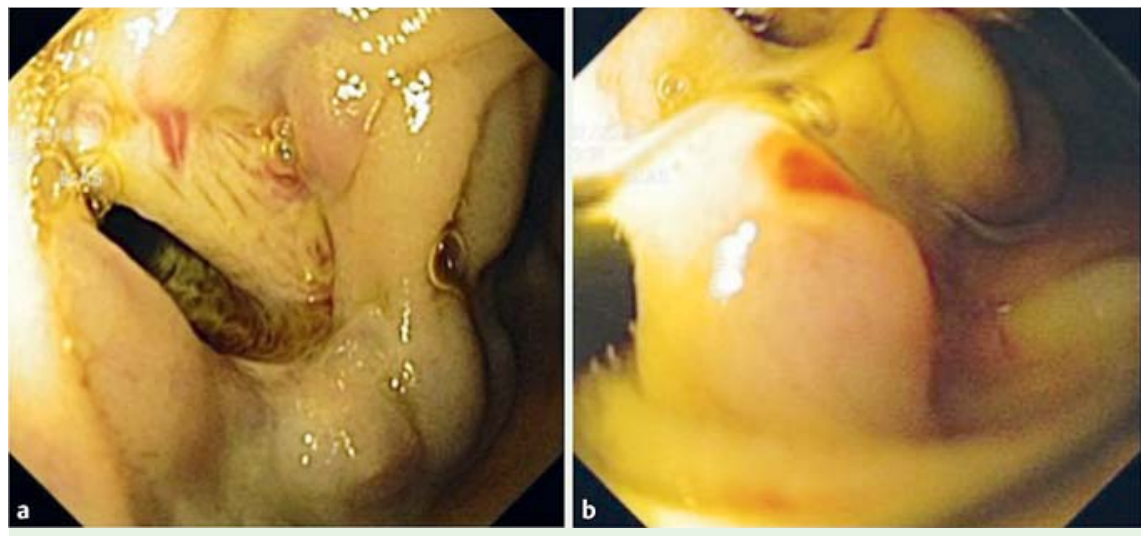

Fig. 1 Views during push enteroscopy in a man with a history of pylorus-preserving pancreatoduodenectomy for pancreatic adenocarcinoma showing: a ectopic varices at a pancreatojejunal anastomosis; $\mathbf{b}$ a rupture point, which was subsequently treated with endoscopic injection therapy.

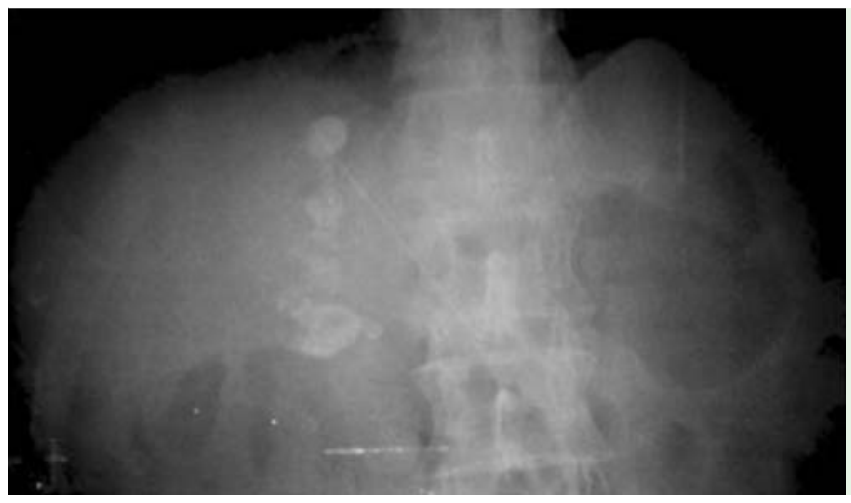

Fig. 2 Abdominal radiograph showing the location and occlusion of the varices after their injection with a mixture of cyanoacrylate and Lipiodol.

Ectopic variceal bleeding is a rare cause of gastrointestinal hemorrhage, representing up to $5 \%$ of all variceal bleeding episodes [1]. The most common cause of ectopic variceal bleeding is portal hypertension (from both intrahepatic and extrahepatic causes) [2]. In the absence of portal hypertension, other causes may include abdominal surgery, abnormalities in the venous outflow vessels, abdominal vascular thrombosis, hepatocellular carcinoma, pancreatitis, and familial syndromes [2,3]. Ectopic variceal bleeding can pose a diagnostic dilemma and endoscopy plays a major role in the diagnosis and treatment of this condition.

A 56-year-old man presented to the emergency room with a 1-week history of melena. The patient's medical history included a pancreatic adenocarcinoma treated 2 years previously with a pyloruspreserving pancreatoduodenectomy and chemotherapy. On admission, his vital signs were stable but the results of a laboratory workup showed severe anemia (hemoglobin $6.4 \mathrm{~g} / \mathrm{dL}$ ).

After he had undergone esophagogastroduodenoscopy (EGD) and colonoscopy, both of which were normal, it was decided to perform a push enteroscopy through the afferent and efferent jejunal limbs. Signs of fresh blood were noted in the afferent limb and the pancreatojejunal anastomosis was reached. At the anastomosis, nodular and bluish vascular dilatations were seen, suggestive of ectopic varices ( $\bullet$ Fig. 1 a). A rupture point was identified ( $\bullet$ Fig. 1 b) and treated with injection of $2 \mathrm{~mL}$ of a mixture of cyanoacrylate and Lipiodol. Post-treatment abdomi-

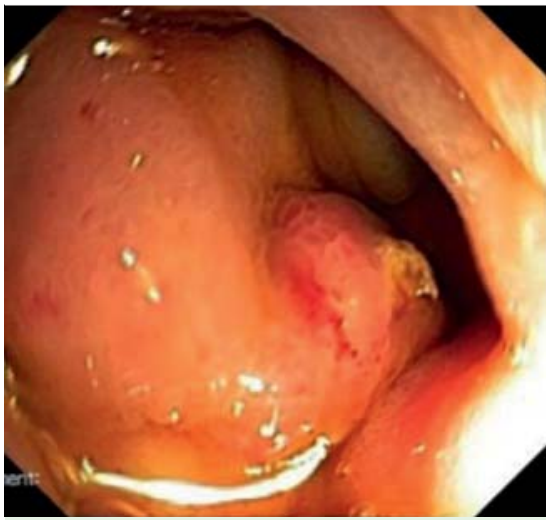

Fig. 3 Follow-up endoscopy 2 weeks later showing obliteration of the ectopic varices.

nal radiography confirmed the location and occlusion of the varices ( $\bullet$ Fig.2). A follow-up endoscopy 2 weeks later revealed obliterated varices ( $\bullet$ Fig.3) and no additional intervention was required. To the authors' knowledge, this is the first report with imaging of ectopic varices in a pancreatojejunal anastomosis. As well as reporting the successful resolution of this unusual situation with conventional endoscopic therapy, we emphasize the appearance of this abnormality with these rare endoscopic images.

\section{Endoscopy_UCTN_Code_CCL_1AC_2AB}

\section{Competing interests: None}

\section{Bruno Moreira Gonçalves ${ }^{1}$, Pedro Bastos' ${ }^{1}$, Pedro Leão ${ }^{2,3,4}$, Carla Rolanda ${ }^{1,3,4}$}

${ }^{1}$ Department of Gastroenterology, Hospital Braga, Braga, Portugal

2 Department of General Surgery, Hospital Braga, Braga, Portugal

${ }^{3}$ Life and Health Sciences Research Institute (ICVS), School of Health Sciences, University of Minho, Braga, Portugal

${ }^{4}$ ICVS/3B's - PT Government Associate Laboratory, Braga/Guimarães, Portugal 


\section{References}

1 Akhter M, Haskal ZJ. Diagnosis and management of ectopic varices. Gastrointest Interv 2012; $1: 3-10$

2 Kastanakis M, Anyfantakis D, Katsougris N et al. Massive gastrointestinal bleeding due to isolated jejunal varices in a patient without portal hypertension. Int J Surg Case Rep 2013; 4: 439-441

3 Helmy A, Kahtani K, Fadda M. Updates in the pathogenesis, diagnosis and management of ectopic varices. Hepatol Int 2008; 2: 322 334
Bibliography

Dol http://dx.doi.org/

10.1055/s-0034-1391871

Endoscopy 2015; 47: E269-E270

(c) Georg Thieme Verlag KG

Stuttgart · New York

ISSN 0013-726X
Corresponding author

Bruno Moreira Gonçalves, MD

Serviço de Gastrenterologia

Hospital de Braga

Sete Fontes - São Victor

4710-243 Braga

Portugal

Fax: +351-25-3027999

brunommgoncalves@gmail.com 